\title{
Developmental Effects of Perfluorononanoic Acid in the Mouse Are Dependent on Peroxisome Proliferator-Activated Receptor-Alpha
}

\author{
Cynthia J. Wolf, ${ }^{1}$ Robert D. Zehr, ${ }^{1}$ Judy E. Schmid, ${ }^{2}$ Christopher Lau, ${ }^{1}$ and Barbara D. Abbott ${ }^{1}$ \\ ${ }^{1}$ Toxicology Assessment Division, National Health and Environmental Effects Research Laboratory, Office of Research and Development, \\ US Environmental Protection Agency, Research Triangle Park, Durham, NC 27711, USA \\ ${ }^{2}$ Research Core Unit, National Health and Environmental Effects Research Laboratory, Office of Research and Development, \\ US Environmental Protection Agency, Research Triangle Park, Durham, NC 27711, USA
}

Correspondence should be addressed to Cynthia J. Wolf, wolf.cynthiaj@epa.gov

Received 17 March 2010; Accepted 12 July 2010

Academic Editor: J. Corton

Copyright (C) 2010 Cynthia J. Wolf et al. This is an open access article distributed under the Creative Commons Attribution License, which permits unrestricted use, distribution, and reproduction in any medium, provided the original work is properly cited.

Perfluorononanoic acid (PFNA) is one of the perfluoroalkyl acids found in the environment and in tissues of humans and wildlife. Prenatal exposure to PFNA negatively impacts survival and development of mice and activates the mouse and human peroxisome proliferator-activated receptor-alpha (PPAR $\alpha$ ). In the current study, we used PPAR $\alpha$ knockout (KO) and 129S1/SvlmJ wild-type (WT) mice to investigate the role of PPAR $\alpha$ in mediating PFNA-induced in vivo effects. Pregnant KO and WT mice were dosed orally with water (vehicle control: $10 \mathrm{ml} / \mathrm{kg}$ ), 0.83, 1.1, 1.5, or $2 \mathrm{mg} / \mathrm{kg}$ PFNA on gestational days (GDs) 1-18 (day of sperm plug = GD 0). Maternal weight gain, implantation, litter size, and pup weight at birth were unaffected in either strain. PFNA exposure reduced the number of live pups at birth and survival of offspring to weaning in the $1.1 \mathrm{and} 2 \mathrm{mg} / \mathrm{kg}$ groups in WT. Eye opening was delayed (mean delay 2.1 days) and pup weight at weaning was reduced in WT pups at $2 \mathrm{mg} / \mathrm{kg}$. These developmental endpoints were not affected in the KO. Relative liver weight was increased in a dose-dependent manner in dams and pups of the WT strain at all dose levels but only slightly increased in the highest dose group in the KO strain. In summary, PFNA altered liver weight of dams and pups, pup survival, body weight, and development in the WT, while only inducing a slight increase in relative liver weight of dams and pups at $2 \mathrm{mg} / \mathrm{kg}$ in KO mice. These results suggest that PPAR $\alpha$ is an essential mediator of PFNA-induced developmental toxicity in the mouse.

\section{Introduction}

Perfluorinated alkyl acids (PFAAs) are a family of chemicals that have a fatty acid-like carbon backbone saturated with fluorine and a functional group at the end. They are surfactants used in many consumer and industrial applications such as waterproofing and stain repellent on clothing, carpets, and other fabrics, oil repellent on food packaging, fire-fighting foams, paints, adhesives, hydraulic fluids, among others [1-4]. Their widespread use in consumer and industrial products is matched by their global presence in the environment $[2,5,6]$ and in wildlife and humans [712]. The ubiquitous presence of these chemicals, especially in human sera, has led to concern about their safety. The two most common PFAAs, perfluorooctanoic acid (PFOA) and perfluorooctane sulfonate (PFOS), have been found in laboratory animals to induce hepatotoxicity, carcinogenicity, immunotoxicity, disruption of thyroid hormone levels, and developmental effects including prenatal and neonatal mortality, stunted mammary gland development, developmental delay, and reduced body weight (reviewed $[6,13]$ ). Although the manufacture of PFOS was phased out in the United States and the manufacture of PFOA is being phased out, alternative PFAAs have been marketed for use.

Perfluorononanoic acid (PFNA) is a 9-carbon member of the PFAA family found in the environment and in serum at levels much lower than those of PFOA or PFOS. Nevertheless, levels of PFNA in human serum have risen in the last several years and currently stand at around $1 \mathrm{ng} / \mathrm{ml}[7,14]$. Its presence in human serum has been shown to correlate 
with PFNA ingested from food and water [15, 16]. Few studies have investigated its toxicity. In vitro studies found PFNA to be cytotoxic in HCT-116 cells [17], and hepatotoxic [18]. PFNA was also found to be immunotoxic in vivo $[19,20]$. More recently, PFNA was found to induce developmental toxicity in mice when administered throughout the gestational period [21]. Adverse effects of exposure to PFNA during gestation include reduced postnatal survival at $5 \mathrm{mg} / \mathrm{kg} /$ day, delayed eye opening, delayed puberty, increased liver weight, and reduced body weight at 3 and $5 \mathrm{mg} / \mathrm{kg} /$ day.

One of the mechanisms implicated in the toxicity of the PFAAs is the activation of peroxisome proliferator-activated receptor-alpha $(\operatorname{PPAR} \alpha)$. PPAR $\alpha$ is a nuclear receptor that plays a role in regulating lipid and glucose homeostasis, cell proliferation and differentiation, and inflammation [22]. PPAR $\alpha$ activation is thought to be responsible for PFOA-induced hepatotoxicity in rodents [23] and certain immunotoxic effects $[20,24,25]$. In addition to PFOA, a number of other PFAAs activate PPAR $\alpha$ in vitro [2628]. PPAR $\alpha$ may mediate developmental processes, since PPAR $\alpha$ is present during murine development [29]. The developmental toxicity of PFOA in mice, including neonatal lethality, delayed eye opening, and reduced body weight, was found to be dependent on PPAR $\alpha$ [30] although developmental toxicity of PFOS was not [31]. PPAR $\alpha$ may also mediate PFNA effects. Evidence of PPAR $\alpha$ activation was found in livers of mice exposed to PFNA during fetal development [21]. PFNA also activates PPAR $\alpha$ in vitro and was the most effective of the PFAAs tested in activating both human and murine PPAR $\alpha$ in transfected COS-1 cells [28]. It is therefore logical to postulate that the developmental toxicity of PFNA, like PFOA, may also be dependent on PPAR $\alpha$.

In the current study, we sought to determine whether PFNA-induced developmental toxicity in the mouse requires expression of PPAR $\alpha$. Pregnant 129S1/SvlmJ wild-type (WT) and PPAR $\alpha$ knockout (KO) mice were given PFNA during gestation, and indices of fertility and neonatal development, along with serum levels of PFNA, were evaluated. We report that the developmental effects of PFNA including pup survival, eye opening, and body weight are dependent on PPAR $\alpha$ and that hepatomegaly is primarily PPAR $\alpha$ dependent but may utilize other pathways as well.

\section{Materials and Methods}

2.1. Animals. Male and female wild-type (WT) 129 S1/SvlmJ mice (stock no. 002448) and PPAR $\alpha$ knockout (KO) mice on a 129S1/SvlmJ background (Ppara-tm1Gonz/J, stock no. 003580) were obtained from Jackson Laboratories (Bar Harbor, ME). WT and KO mice were kept in breeding colonies in the EPA Reproductive Toxicology Facility, Durham, NC. Colony animals were group housed by sex in Tecniplast cages (Tecniplast USA, Exton, PA) with Beta-chip hardwood bedding (Northeastern Products, Warrensburg, NY) in a closed ventilation system, provided pelleted mouse chow (LabDiet 5001, PMI Nutrition International LCC, Brentwood, MO) and tap water ad libitum, and kept in an atmosphere of $68-74^{\circ} \mathrm{F}$ and $40-60 \%$ humidity with a 12 -hour light-dark cycle. All animal studies were conducted in accordance with guidelines established by the USe EPA ORD/NHEERL Institutional Animal Care and Use Committee. Procedures and facilities were consistent with the recommendations of the 1996 NRC "Guide for the Care and Use of Laboratory Animals", the Animal Welfare Act, and Public Health Service Policy on the Humane Care and Use of Laboratory Animals.

2.2. Study Design and Protocol. The study was conducted in four blocks with WT and KO represented in each block. WT and KO females were mated overnight to males of their respective strain, one mating pair per cage. Females were checked for vaginal plugs the following morning and plug positive animals were weighed, randomly assigned to treatment groups, and housed individually in regular ventilated polypropylene cages. Day of plug was considered gestational day (GDs) 0 . Animals of each strain were weighed and dosed by oral gavage once daily on GD 1-18 with either water (vehicle control: $10 \mathrm{ml} / \mathrm{kg}$ ) or PFNA (CAS\# 375-951; $97 \%$ pure; Aldrich, St. Louis, MO) at 0.83, 1.1, 1.5, or $2.0 \mathrm{mg} / \mathrm{kg}$, based on previous studies with PFNA and PFOA $[21,30]$. Dosing solutions were prepared by dilution, fresh daily immediately before dosing. At term, adult females were checked twice daily for the presence of pups. Adult females with pups or those were pregnant were called dams. Day of birth was considered postnatal day (PND) 0. Dams and pups were monitored on a daily basis. The numbers of live and dead pups were recorded twice daily, and live pups were weighed by sex on postnatal days $0,1,2,3$, $7,10,14$, and 21 (weaning). Pups were monitored for eye opening daily from PND 11 until all eyes were open. Eye opening is described as the percentage of pups per litter having both eyes completely open and was identified by technicians trained by demonstration and protocol to eliminate subjectivity. All animals on study were sacrificed for necropsy on PND 21 (42 days postcoitus for nonpregnant adult females). Body and liver weights were measured from each adult female and from 2 pups per litter. Blood was collected from each dam individually and from all pups pooled by litter. Serum was extracted and stored at $-20^{\circ} \mathrm{C}$. Uteri were collected from all adult females, stained with $2 \%$ ammonium sulfide, and uterine implantation sites were counted [32].

2.3. Serum Analysis of PFNA. Analysis of PFNA in serum was performed using a modification of a method previously described in [33]. For the current study, $25 \mu \mathrm{l}$ of serum was placed in a $6 \mathrm{ml}$ polypropylene tube, deproteinized with $1 \mathrm{ml}$ of $0.1 \mathrm{M}$ formic acid, and vortexed. Two hundred $\mu \mathrm{l}$ of this mixture was then transferred to a fresh $6 \mathrm{ml}$ polypropylene tube and spiked with $2 \mathrm{ml}$ acetonitrile containing $25 \mathrm{ng} / \mathrm{ml}$ ${ }^{13} \mathrm{C}_{9}$-PFNA (Cambridge Isotope Laboratories, Inc., Andover, MA). The tube was vortexed for 20 minutes and then centrifuged for 3 minutes at $3500 \mathrm{rpm}$ to precipitate proteins or other residue. Two hundred $\mu \mathrm{l}$ of the supernatant was then transferred to a $500 \mu \mathrm{L}$ polypropylene autosampler vial and mixed with $200 \mu \mathrm{l}$ of $2 \mathrm{C} \mathrm{mM}$ ammonium acetate 
for HPLC/MS-MS analysis. Solutions were analyzed using an Agilent 1100 high-performance liquid chromatograph (Agilent Technology, Palo Alto, CA) coupled with an API 3000 triple quadrupole mass spectrometer (LC/MS-MS; Applied Biosystems, Foster City, CA). Ten $\mu$ l of solution was injected onto a Luna C18(2) $3 \times 50 \mathrm{~mm}, 5 \mu \mathrm{m}$ column (Phenomenex, Torrance, CA) using a mobile phase consisting of $30 \% 2 \mathrm{mM}$ ammonium acetate solution and $70 \%$ acetonitrile. Peak integrations and areas were determined using Analyst software (Applied Biosystems Version 1.4.1). For each analytical batch, matrix-matched calibration curves were prepared using mouse serum spiked with varying levels of PFNA (Aldrich, St. Louis, MO). For quality control, check standards were prepared by spiking large volumes of mouse serum at several arbitrary levels. Check standards were stored frozen and aliquots analyzed with each analytical set. In addition, control mouse serum samples were fortified at two or three levels in duplicate with known quantities of PFNA during the preparation of each analytical set. Duplicate fortified and several check standards were run in each analytical batch to assess precision and accuracy. The limit of quantitation (LOQ) was set as the lowest calibration point on the standard curve. Analytical batches were considered to be acceptable if matrix and reagent blanks had no significant PFNA peaks approaching the LOQ, the standard curve had a correlation coefficient $>0.98$, and all standard curve points, fortified, and check samples were within $70 \%-130 \%$ of the theoretical and previously determined values, respectively.

2.4. Data Analysis. Maternal pregnancy, neonatal development, and necropsy data were analyzed in GraphPad Prism (version 4; San Diego, CA). Individual means (maternal data) or litter means (pup data) and standard errors were obtained by dose group and strain and analyzed by ANOVA. Pairwise $t$-tests were computed within ANOVA to compare individual treatment groups to relevant control groups within strain. A Bonferroni multiple-comparison adjustment was used when appropriate. Linear regression analysis was performed on liver data to detect dose-related trends. Pregnancy rate was analyzed using chi-square trend analysis. Litter loss is described as dams that had full litter resorption (FLR, uterine implants but no pups at birth) or whole litter loss (WLL, only dead pups at birth). Litter loss was examined for treatment effect using chi-square analysis. Serum data were analyzed in SAS for Windows v9.1 (SAS, Cary, NC). Analyses were performed separately for adult females and for pups. Adult females were further separated into pregnancy and lactation status (with live pups or with no live pups including nonpregnant and litter loss). A subset of dams matched with their pups was used to determine differences in levels of PFNA between dams and pups. Where variances were heterologous, data were $\log 10$ transformed to calculate means and standard errors and analyzed by ANOVA to investigate effects of treatment, strain (WT, KO), and block. When treatment differences were found by ANOVA, pairwise $\mathrm{t}$-tests between treatment groups were calculated within each strain and separately by dams or pups, using Tukey-Kramer adjustment for multiple comparisons where appropriate.

\section{Results}

3.1. Maternal Pregnancy Outcome and Gestational Body Weight. Daily maternal body weight and maternal weight gain from GD 1 to GD 18 were not affected by gestational PFNA exposure. Implantation and total litter size (live and dead pups) at birth were not affected in either strain. However, the number of live pups at birth was significantly reduced in the WT strain at $1.1(P<.05)$ and $2.0(P$ $<.001) \mathrm{mg} / \mathrm{kg}$ PFNA (Table 1) while being not significant at $1.5 \mathrm{mg} / \mathrm{kg}$. Percent litter loss was not significantly altered in any dose group in $\mathrm{KO}$ or WT although there was a modest but insignificant increase in litter loss in the WT (Table 1). In each dose group in the $\mathrm{KO}$, only 1 or 2 dams had FLR or WLL while, in the WT group, exposed to $2 \mathrm{mg} / \mathrm{kg}$ PFNA, 4 dams had FLR and 2 had WLL (35\% litter loss). Most dams with FLR did not gain weight comparable to the pregnant dams that delivered litters, which suggests that FLR occurred early in gestation. Dams with WLL gained weight and carried to term, but it cannot be determined by our protocol whether these pups died prior to delivery or soon after delivery. Pregnancy rate, the percentage of plugged mice that had uterine implants, was reduced in treated $\mathrm{KO}$ groups $(P<.001)$ but not in WT groups, suggesting that PFNA may have interfered with implantation when PPAR $\alpha$ was not functional.

3.2. Pup Survival, Development, and Body Weight. The reduced viability of pups at birth in the WT at 1.1 and $2 \mathrm{mg} / \mathrm{kg}$ continued through the postnatal period. Survival of WT pups from birth to weaning (PND 21) was greatly reduced at $1.1(P<.05)$ and $2(P<.001) \mathrm{mg} / \mathrm{kg}$ PFNA (Figure 1). By PND 21, survival of pups in the WT 1.1 and $2.0 \mathrm{mg} / \mathrm{kg}$ groups was reduced to $36 \%$ and $31 \%$, respectively. In contrast, survival was not affected in the $\mathrm{KO}$ at any dose.

Eye opening was used as a marker of postnatal development. The mean day of eye opening in the controls was PND $13.7 \pm 0.3$ in WT and PND $13.9 \pm 0.2$ in KO. The mean day of eye opening was significantly delayed at $2 \mathrm{mg} / \mathrm{kg}$ PFNA in the WT by two days, to PND $15.8 \pm 0.2(P<.01)$, but not at any other dose. In contrast, the mean day of eye opening was not affected at any dose in KO. The percent of eyes open on PNDs $13,14,15$, and 16 was also significantly reduced in the WT at $2 \mathrm{mg} / \mathrm{kg}$ PFNA while being not affected in the KO (Figure 2).

Pup birth weight was not affected by any dose of PFNA in WT or KO, either in males or females (Table 2). Although pup body weight was not different among groups at birth, pup body weight was reduced in both male and female WT pups in the $2 \mathrm{mg} / \mathrm{kg}$ group at several time points during the postnatal period, beginning at PND 7 and including weaning (Figure 3). Weight gain during this period was reduced in WT female pups from $8.52 \mathrm{~g}$ in controls to $6.35 \mathrm{~g}$ in the $2 \mathrm{mg} / \mathrm{kg}$ group $(P<.001)$, but not in male. In contrast, body weight and weight gain were not affected at any age at any dose level in the $\mathrm{KO}$ (Figure 3).

3.3. Liver Weight and Body Weight at PND21. Absolute liver weight was increased in a dose-dependent fashion in 
TABLE 1: Effects of gestational administration (GD 1-18) of PFNA to wild type and PPAR $\alpha$ KO mice on maternal weight and reproductive outcomes.

\begin{tabular}{|c|c|c|c|c|c|c|c|c|c|}
\hline Strain & $\begin{array}{l}\text { Dose } \\
(\mathrm{mg} / \mathrm{kg} / \text { day })\end{array}$ & $\begin{array}{l}\text { No. of } \\
\text { pregnant }^{\text {a }}\end{array}$ & $\begin{array}{l}\text { Maternal } \\
\text { Weight Gain } \\
\text { GD1-18 }(\mathrm{g})\end{array}$ & $\begin{array}{l}\text { Maternal } \\
\text { Weight } \\
\text { GD18 }^{\mathrm{b}}(\mathrm{g})\end{array}$ & $\begin{array}{l}\text { No. of uterine } \\
\text { implants }\end{array}$ & $\begin{array}{l}\text { Total no. of } \\
\text { Pups per litter } \\
\text { (live }+ \text { dead) }\end{array}$ & $\begin{array}{l}\text { No. of live } \\
\text { pups per } \\
\text { litterc }^{\text {c }}\end{array}$ & $\begin{array}{l}\% \text { Litter } \\
\text { loss }^{\mathrm{d}}\end{array}$ & $\begin{array}{l}\text { Pregnancy } \\
\text { rate }^{\mathrm{e}}(\%)\end{array}$ \\
\hline \multirow{5}{*}{ WT } & 0 & 14 & $10.8 \pm 0.98$ & $34.4 \pm 0.8$ & $8.5 \pm 0.6$ & $7.1 \pm 0.56$ & $6.8 \pm 0.70$ & 14.3 & 53.8 \\
\hline & 0.83 & 11 & $12.8 \pm 0.81$ & $35.0 \pm 1.0$ & $8.5 \pm 0.6$ & $6.8 \pm 0.70$ & $6.1 \pm 0.82$ & 9.1 & 47.8 \\
\hline & 1.1 & 12 & $10.8 \pm 0.57$ & $33.6 \pm 0.4$ & $7.3 \pm 0.5$ & $5.6 \pm 0.50$ & $3.7 \pm 0.37^{*}$ & 16.7 & 35.3 \\
\hline & 1.5 & 14 & $12.6 \pm 0.50$ & $36.0 \pm 0.5$ & $8.4 \pm 0.6$ & $6.2 \pm 0.54$ & $4.7 \pm 0.67$ & 7.1 & 38.9 \\
\hline & 2.0 & 17 & $13.2 \pm 0.74$ & $35.9 \pm 0.9$ & $7.8 \pm 0.6$ & $5.2 \pm 0.54$ & $3.1 \pm 0.73^{* *}$ & 35.3 & 47.2 \\
\hline \multirow{5}{*}{$\mathrm{KO}$} & 0 & 18 & $12.0 \pm 0.49$ & $35.9 \pm 0.6$ & $8.9 \pm 0.4$ & $7.8 \pm 0.36$ & $7.0 \pm 0.41$ & 11.1 & 75.0 \\
\hline & 0.83 & 13 & $11.4 \pm 0.73$ & $34.6 \pm 0.8$ & $8.4 \pm 0.6$ & $7.2 \pm 0.58$ & $7.0 \pm 0.54$ & 7.7 & $65.0^{\dagger}$ \\
\hline & 1.1 & 14 & $11.5 \pm 0.56$ & $35.6 \pm 0.6$ & $9.2 \pm 0.4$ & $8.3 \pm 0.49$ & $7.8 \pm 0.43$ & 7.1 & $58.3^{\dagger}$ \\
\hline & 1.5 & 9 & $12.1 \pm 0.87$ & $35.5 \pm 1.3$ & $9.8 \pm 0.6$ & $8.5 \pm 0.80$ & $8.4 \pm 0.84$ & 11.1 & $20.9^{\dagger}$ \\
\hline & 2.0 & 16 & $11.0 \pm 0.80$ & $33.4 \pm 0.9$ & $8.1 \pm 0.7$ & $6.6 \pm 0.62$ & $6.4 \pm 0.66$ & 12.5 & $43.2^{\dagger}$ \\
\hline
\end{tabular}

Values are means \pm SEM.

KO: PPAR $\alpha$ knockout; WT: wild type; GD: gestational day.

${ }^{\text {a }}$ Pregnancy verified by presence of uterine implantation sites.

${ }^{\mathrm{b}}$ Excludes adult females not pregnant or with full litter resorption.

${ }^{\mathrm{c}}$ Number of pups on day of birth at first observation.

${ }^{\mathrm{d}}$ Litter loss: uterine implants present but no pups (full litter resorption) or only dead pups (whole litter loss) at birth.

ePregnancy rate: (\# pregnant / \# plug +$) * 100$.

${ }^{*} P<.05,{ }^{* *} P<.001$ by Bonferroni's test. ${ }^{\dagger} P<.001$ by chi-square test for trend.

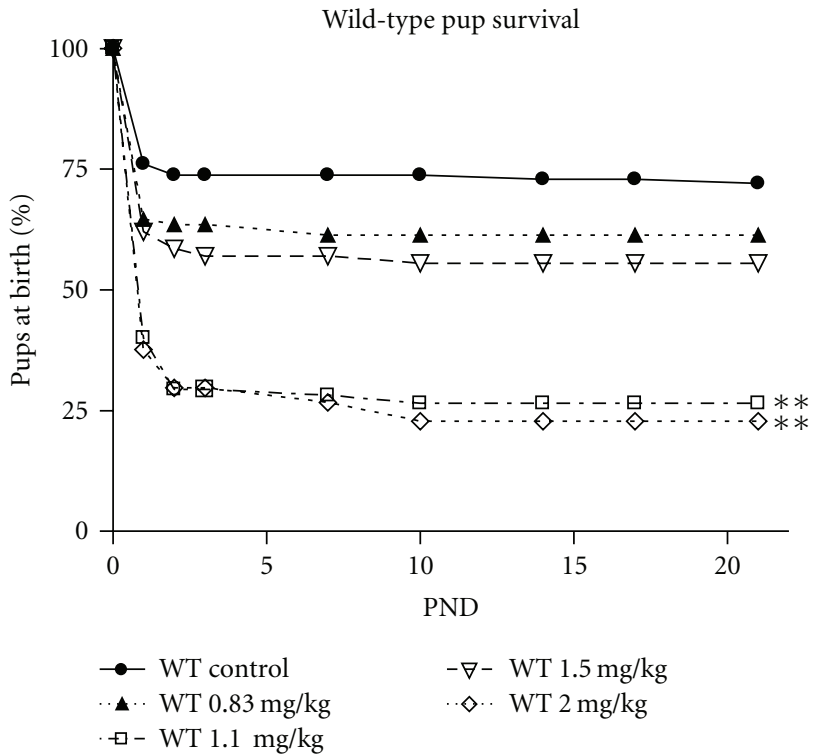

(a)

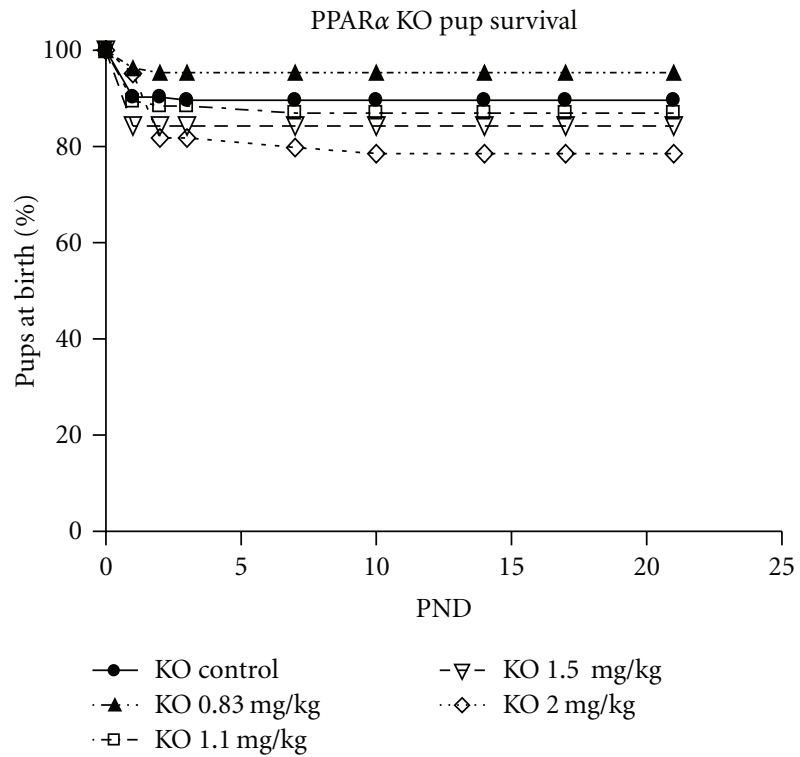

(b)

Figure 1: Effects of prenatal exposure to PFNA on survival of wild-type (WT) and PPAR $\alpha$ knockout (KO) mouse pups. Data represent litter means \pm SEM of the percent of the litter alive on postnatal days $0-3,7,10,14,17$, and 21 . Survival was reduced in WT pups by 1.1 and $2.0 \mathrm{mg} / \mathrm{kg}$ PFNA on GDs $1-18$. Asterisks denote a significant difference $(P<.001)$ found by ANOVA and Bonferroni's test for multiple comparisons. PND: postnatal day.

all PFNA-treated groups in WT adult females, regardless of prior pregnancy status. In $\mathrm{KO}$ adult females, however, liver weight was not affected by PFNA in dams but was increased in the 1.5 and $2.0 \mathrm{mg} / \mathrm{kg}$ groups in the nonpregnant adult (Table 3 ). In addition, among the nonpregnant adults, the dose dependent increase in liver weight was lower in KO compared to WT $(P<.0001$, by regression analysis $)$. Similarly, relative liver weight was increased in a dosedependent fashion in all treated groups in the WT $(P<.001)$, regardless of pregnancy history, and in $1.1 \mathrm{mg} / \mathrm{kg}$ and higher 


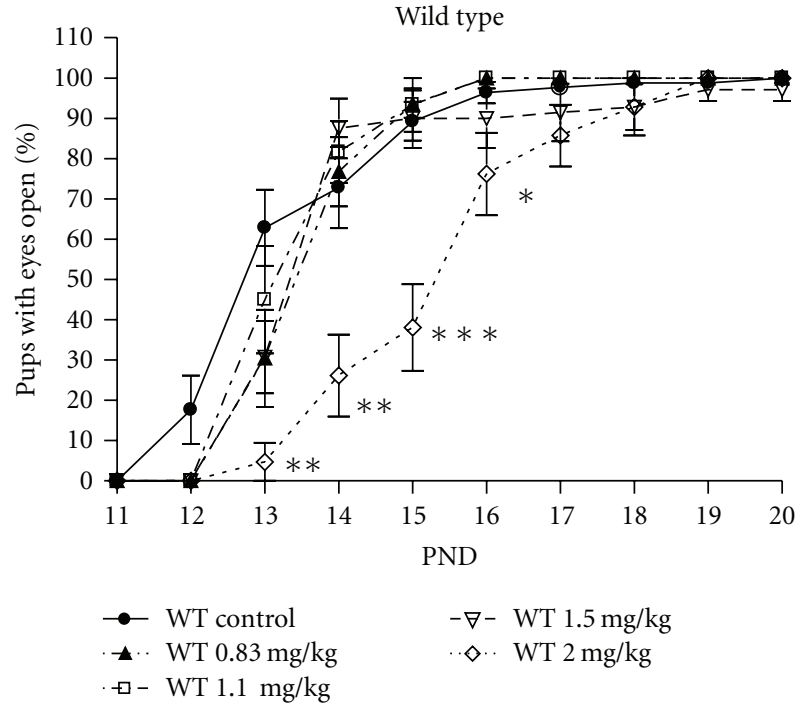

(a)

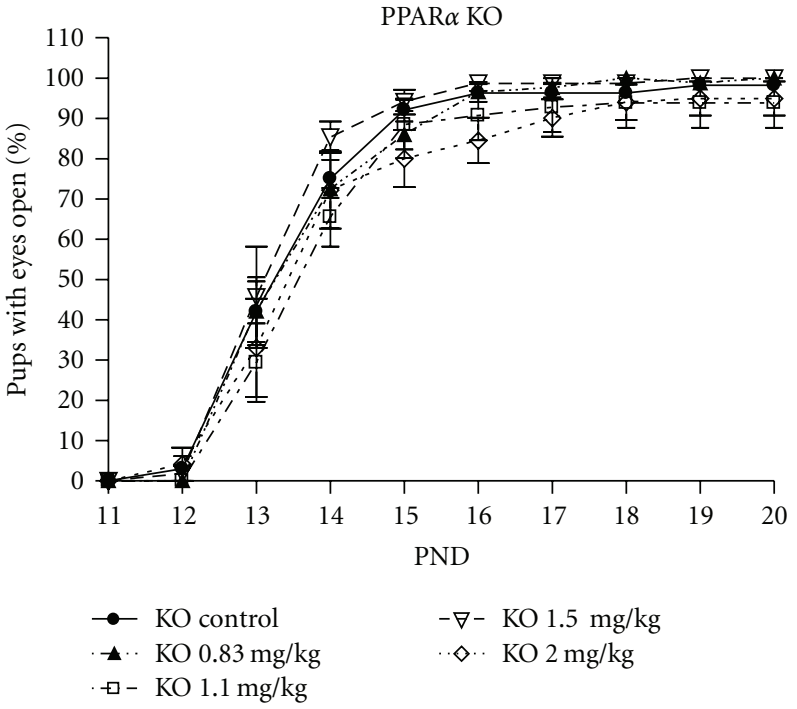

(b)

FIGURE 2: Effect of prenatal exposure to PFNA on the percent of eyes open on postnatal days 13-16 in wild-type (WT) and PPAR $\alpha$ knockout $(\mathrm{KO})$ mouse pups. Data represent litter means \pm SEM of the percent of the litter with pups having both eyes fully open. A reduction in the percent of eyes open was found in the WT pups exposed to $2 \mathrm{mg} / \mathrm{kg}$ PFNA. Differences were found by ANOVA and Bonferroni's test for multiple comparisons. Asterisks denote a significant difference $\left({ }^{*} P<.05,{ }^{* *} P<.01,{ }^{* * *} P<.0001\right)$. PND: postnatal day.

TABLE 2: Birth weights of wild type and PPAR $\alpha$ KO mouse pups after in utero exposure to PFNA on GD 1-18.

\begin{tabular}{llclcl}
\hline & $\begin{array}{l}\text { Dose } \\
(\mathrm{mg} / \mathrm{kg} / \text { day })\end{array}$ & $n$ & $\begin{array}{l}\text { Male weight } \\
(\mathrm{g})\end{array}$ & $n$ & $\begin{array}{l}\text { Female weight } \\
(\mathrm{g})\end{array}$ \\
\hline \multirow{4}{*}{$\mathrm{WT}$} & 11 & $1.28 \pm 0.03$ & 12 & $1.26 \pm 0.03$ \\
& 0.83 & 8 & $1.28 \pm 0.03$ & 10 & $1.30 \pm 0.05$ \\
& 1.1 & 10 & $1.29 \pm 0.06$ & 10 & $1.34 \pm 0.06$ \\
& 1.5 & 11 & $1.33 \pm 0.03$ & 12 & $1.32 \pm 0.03$ \\
& 2.0 & 9 & $1.41 \pm 0.06$ & 8 & $1.30 \pm 0.05$ \\
\hline \multirow{4}{*}{$\begin{array}{l}\text { KO } \\
0.83\end{array}$} & 16 & $1.24 \pm 0.03$ & 16 & $1.19 \pm 0.02$ \\
& 1.1 & 12 & $1.28 \pm 0.03$ & 12 & $1.25 \pm 0.03$ \\
& 1.5 & 8 & $1.25 \pm 0.04$ & 13 & $1.20 \pm 0.03$ \\
& 2.0 & 10 & $1.26 \pm 0.03$ & 14 & $1.29 \pm 0.05$ \\
\hline
\end{tabular}

Values are litter means \pm SEM. $n$ : no. of litters. WT: wild type; KO: PPAR $\alpha$ knockout; $n$ : number of litters.

doses in the nonpregnant $\mathrm{KO}$ (Figure 4). In $\mathrm{KO}$ adults that had been pregnant, relative liver weight was unaffected. Body weight at necropsy was generally unaffected by dose or strain (Table 3). Absolute liver weight was increased in all PFNA dose groups in WT pups but was unaffected in KO. Relative liver weight was increased in all dose groups in WT pups but in only the highest dose group, $2 \mathrm{mg} / \mathrm{kg}$, in $\mathrm{KO}$ (Figure 4). Body weight was not reduced in $\mathrm{KO}$ pups at any dose. Pup body weight was reduced in WT at $2 \mathrm{mg} / \mathrm{kg}$ only (Table 3 ).

3.4. Serum PFNA Levels. PFNA was detected in serum of all animals (Table 4). PFNA levels were significantly higher in PFNA-treated mice at every dose level compared to controls
$(P<.0001)$ and levels increased in a dose-dependent fashion. Serum PFNA levels were higher in adult females with no live pups (regardless of pregnancy) compared to adults with live pups by $P<.001(\mathrm{KO})$ and $P<.005$ (WT). PFNA levels were also higher in pups compared to their dams, based on a subset of dams matched to their existing pups at weaning (KO, $P<.0001$; WT, $P<.005$ ). In all dams with nursing pups, PFNA levels were lower in KO compared to WT $(P<.001)$ while, in pups, PFNA levels were higher in KO compared to WT $(P<.0001$; Table 4$)$.

\section{Discussion}

Perfluorononanoic acid (PFNA) has recently been shown to induce developmental toxicity and liver enlargement in mice [21], as do other perfluoroalkyl acids. The purpose of the current study was to determine whether these effects are dependent on PPAR $\alpha$, using the 129S/SvlmJ PPAR $\alpha$ knockout (KO) mouse model. Gestational exposure to PFNA reduced neonatal survival and body weight through the weaning period, delayed eye opening, and increased absolute liver weight in the WT offspring at doses as low as $0.83 \mathrm{mg} / \mathrm{kg} / \mathrm{day}$. By contrast, these effects were not seen in KO offspring. These findings demonstrate that PFNA is a developmental toxicant and its effects are dependent on expression of PPAR $\alpha$.

This pattern of reduced survival, body weight, delayed development, and increased liver weight is common to most perfluoroalkyl acids (PFAAs) studied thus far. These effects have been reported in rodents for PFOA [30, 34], PFOS, [31, 35, 36], and PFNA [[21, 37], Das, 2010 \#389], with a few specific differences that may be due to strain, dosing regimen, and the chain length and functional group of the PFAA. Such 


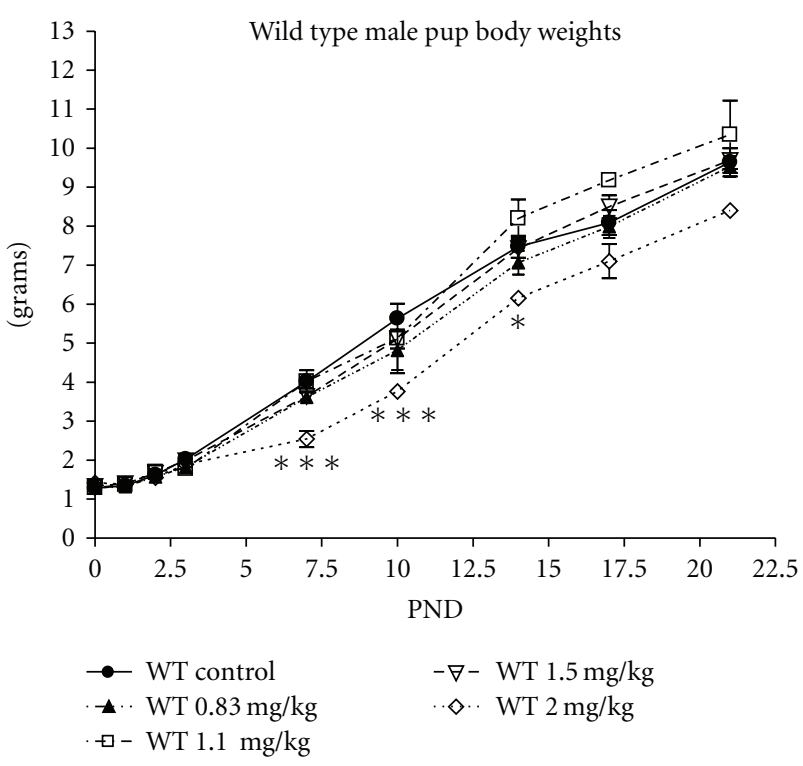

(a)

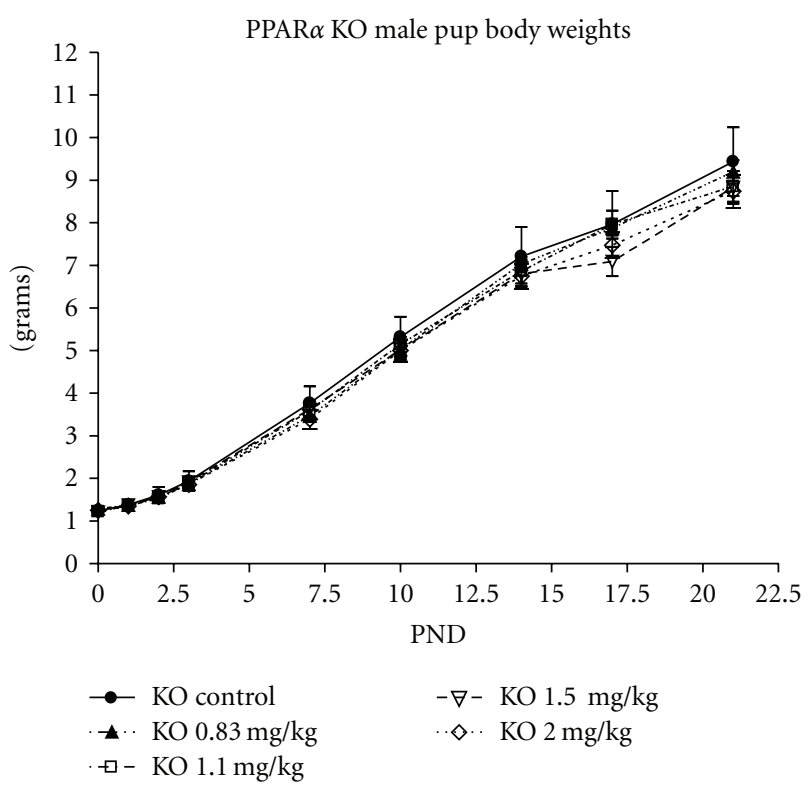

(c)

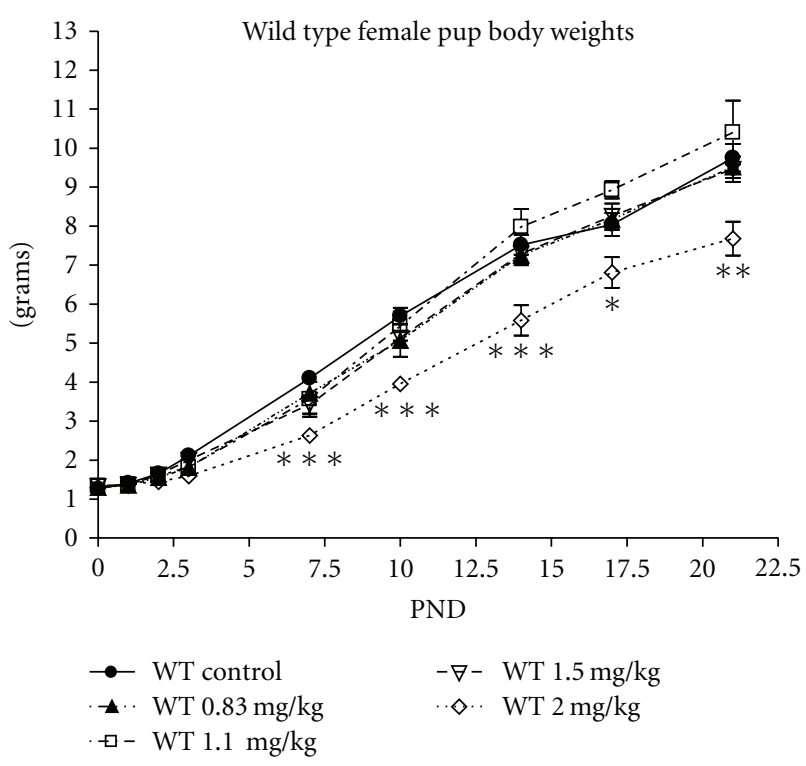

(b)

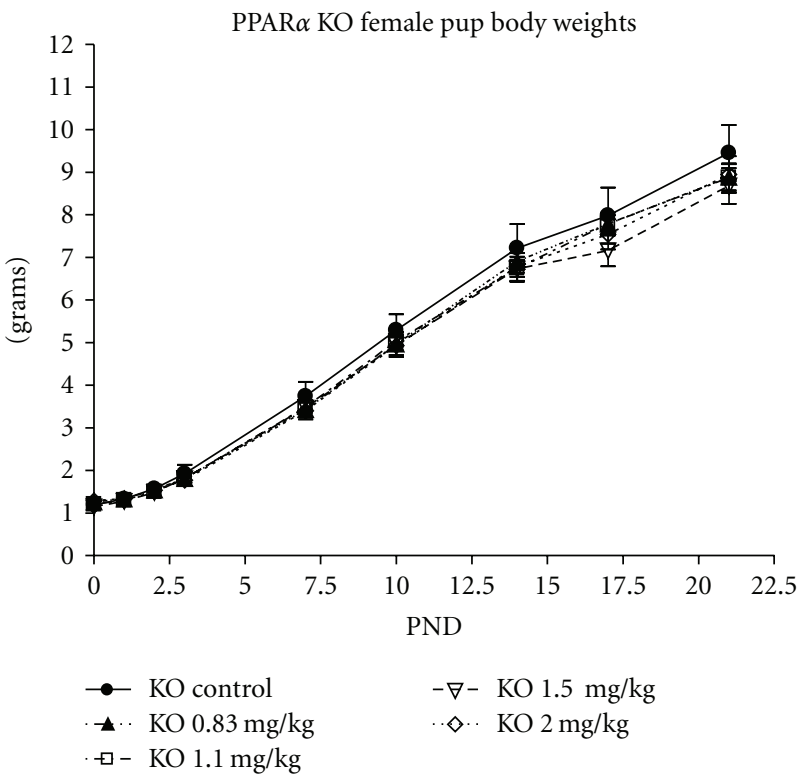

(d)

FIGURe 3: Effects of prenatal exposure to PFNA on postnatal body weights of wild-type (a, b) and PPAR $\alpha$ knockout (c, d) male (a, c) and female $(b, d)$ pups. Data represent litter means \pm SEM on postnatal days $0-3,7,10,14,17$, and 21 . Body weights of WT pups were reduced by $2 \mathrm{mg} / \mathrm{kg}$ PFNA on postnatal days 7, 10, and 14, in male pups and days 7-21 in females. No effect on body weight was found in KO pups. Significant differences were found by ANOVA, and differences between groups were found by Bonferroni's test for multiple comparisons. Asterisks denote a significant difference $\left({ }^{*} P<.05\right.$ by $t$-test, ${ }^{* *} P<.01$, $\left.{ }^{* * *} P<.001\right)$.

studies also obtained effects in offspring at dose levels that are not maternally toxic $[30,31,34,35,38]$, as shown here. Also common to the current and previous studies, the liver was the most sensitive target tissue, with effects on liver weight seen in both WT dam and pup from the lowest dose level of PFNA used in the study, $0.83 \mathrm{mg} / \mathrm{kg}$, and higher. Reduced survival, body weight, and delayed eye opening in pups were also sensitive endpoints, inducing effects at the next higher dose levels, 1.1 and/or $2.0 \mathrm{mg} / \mathrm{kg}$. Survival and number of live pups at birth were compromised at $1.5 \mathrm{mg} / \mathrm{kg}$, but the values did not reach statistical significance. The reason for this finding is unclear. The serum PFNA concentrations and the liver weight in the pups in this dose group were in the expected ranges for a linear dose-response curve, suggesting proper dose preparation and administration for $1.5 \mathrm{mg} / \mathrm{kg}$. In addition, the " $n$ " of 12 litters in this treatment group was comparable to that of other dose groups, so it seems unlikely that the outcome is related to a low statistical 
TABLE 3: Liver and body weights (grams) of wild type and PPAR $\alpha$-KO adult females and pups at necropsy (PND 21) after exposure to PFNA on GD 1-18.

\begin{tabular}{cccccccc}
\hline \multirow{2}{*}{ Strain } & \multirow{2}{*}{ Dose $(\mathrm{mg} / \mathrm{kg} /$ day) } & \multicolumn{3}{c}{ Adult females (NP) } & \multicolumn{2}{c}{ Adult females (P) } & \multicolumn{2}{c}{ Pups (sexes combined) } \\
& & Liver Weight & Body Weight & Liver Weight & Body Weight ${ }^{\mathrm{a}}$ & Liver Weight & Body Weight \\
\hline & 0 & $0.86 \pm 0.03$ & $22.7 \pm 0.42$ & $1.52 \pm 0.87$ & $27.3 \pm 0.58$ & $0.381 \pm 0.02$ & $9.62 \pm 0.36$ \\
& 0.83 & $1.49 \pm 0.04^{* *}$ & $22.9 \pm 0.48$ & $1.65 \pm 0.07$ & $26.4 \pm 0.56$ & $0.551 \pm 0.03^{* *}$ & $9.79 \pm 0.30$ \\
WT & 1.1 & $1.80 \pm 0.04^{* *}$ & $24.0 \pm 0.43$ & $1.91 \pm 0.10^{*}$ & $26.2 \pm 0.72$ & $0.649 \pm 0.05^{* *}$ & $10.34 \pm 0.61$ \\
& 1.5 & $1.86 \pm 0.05^{* *}$ & $23.0 \pm 0.56$ & $2.24 \pm 0.05^{* *}$ & $28.2 \pm 0.66$ & $0.608 \pm 0.02^{* *}$ & $9.47 \pm 0.23$ \\
& 2.0 & $2.18 \pm 0.04^{* *}$ & $24.2 \pm 0.36$ & $2.51 \pm 0.07^{* *}$ & $27.5 \pm 0.70$ & $0.518 \pm 0.01^{* *}$ & $7.56 \pm 0.42^{* *}$ \\
& 0 & $0.99 \pm 0.04$ & $24.8 \pm 0.74$ & $1.88 \pm 0.06$ & $29.1 \pm 0.32$ & $0.417 \pm 0.01$ & $9.35 \pm 0.19$ \\
& 0.83 & $1.20 \pm 0.04$ & $24.7 \pm 1.00$ & $1.77 \pm 0.06$ & $28.3 \pm 0.38$ & $0.421 \pm 0.01$ & $9.16 \pm 0.28$ \\
\hline KO & 1.1 & $1.17 \pm 0.07$ & $23.2 \pm 0.54$ & $2.02 \pm 0.05$ & $29.6 \pm 0.40$ & $0.429 \pm 0.02$ & $9.18 \pm 0.26$ \\
& 1.5 & $1.45 \pm 0.04^{* *}$ & $23.8 \pm 0.41$ & $1.74 \pm 0.16$ & $26.2 \pm 1.32^{*}$ & $0.422 \pm 0.02$ & $8.51 \pm 0.34$ \\
& 2.0 & $1.53 \pm 0.04^{* *}$ & $23.4 \pm 0.28$ & $1.96 \pm 0.10$ & $28.0 \pm 0.77$ & $0.489 \pm 0.03$ & $8.98 \pm 0.40$ \\
\hline
\end{tabular}

Values are means \pm SEM.

Pup weights were on 2 pups per litter. NP: not pregnant; P: pregnant; WT: wild type; KO: PPAR $\alpha$ knockout; Wt: weight.

NP includes those with full litter resorption and no weight gain; P includes those who gave birth whether pups were live or dead.

${ }^{a} P<.05$ compared to NP females body weight. ${ }^{*} P<.05,{ }^{*} P<.001$ compared to controls within column and strain. See text for other comparisons.

TABle 4: Serum PFNA concentrations at weaning in PPAR $\alpha$-KO and WT Adult female mice and offspring exposed to PFNA on GD 1-18.

\begin{tabular}{|c|c|c|c|c|c|c|c|}
\hline \multirow{2}{*}{ Strain } & \multirow{2}{*}{ Dose $(\mathrm{mg} / \mathrm{kg} /$ day $)$} & \multicolumn{2}{|c|}{ Adult females with no live pups } & \multicolumn{2}{|c|}{ Adult females with live pups } & \multicolumn{2}{|c|}{ Pups (sexes combined) } \\
\hline & & $n$ & PFNA $(\mu \mathrm{g} / \mathrm{ml})$ & $n$ & PFNA $(\mu \mathrm{g} / \mathrm{ml})$ & $n$ litters & PFNA $(\mu \mathrm{g} / \mathrm{ml})$ \\
\hline \multirow{5}{*}{ WT } & 0 & 14 & $0.067 \pm 0.005$ & 12 & $0.022 \pm 0.004$ & 9 & $0.033 \pm 0.008$ \\
\hline & 0.83 & 13 & $28.5 \pm 1.22^{\mathrm{a}}$ & 10 & $8.91 \pm 1.51^{\mathrm{a}}$ & 8 & $9.60 \pm 9.37^{\mathrm{a}}$ \\
\hline & 1.1 & 26 & $39.7 \pm 1.26^{\mathrm{a}}$ & 10 & $23.2 \pm 2.57^{\mathrm{a}}$ & 5 & $15.7 \pm 1.42^{\mathrm{a}}$ \\
\hline & 1.5 & 23 & $48.4 \pm 1.54^{\mathrm{a}}$ & 13 & $21.0 \pm 3.01^{\mathrm{a}}$ & 10 & $17.5 \pm 1.15^{\mathrm{a}}$ \\
\hline & 2.0 & 26 & $64.0 \pm 2.46^{\mathrm{a}}$ & 11 & $35.3 \pm 3.90^{\mathrm{a}}$ & 7 & $25.3 \pm 2.70^{\mathrm{a}}$ \\
\hline \multirow{5}{*}{$\mathrm{KO}$} & 0 & 9 & $0.048 \pm 0.008$ & 16 & $0.016 \pm 0.001$ & 16 & $0.068 \pm 0.027$ \\
\hline & 0.83 & 8 & $38.4 \pm 2.34^{\mathrm{a}}$ & 11 & $2.76 \pm 0.172^{\mathrm{a}}$ & 12 & $15.2 \pm 1.01^{\mathrm{a}}$ \\
\hline & 1.1 & 11 & $53.9 \pm 2.51^{\mathrm{a}}$ & 13 & $4.17 \pm 0.310^{\mathrm{a}}$ & 12 & $19.4 \pm 0.69^{\mathrm{a}}$ \\
\hline & 1.5 & 37 & $72.1 \pm 2.91^{\mathrm{a}}$ & 8 & $11.8 \pm 5.71^{\mathrm{a}}$ & 7 & $26.4 \pm 1.39^{\mathrm{a}}$ \\
\hline & 2.0 & 23 & $83.4 \pm 2.93^{\mathrm{a}}$ & 15 & $22.6 \pm 5.69^{\mathrm{a}}$ & 12 & $38.4 \pm 1.80^{\mathrm{a}}$ \\
\hline
\end{tabular}

Values are means \pm SEM or litter means \pm SEM. Serum was collected from all adult females and from 2 pups per litter at 23 days post dose.

WT: wild type; KO: PPAR $\alpha$ knockout.

a Significantly different from control values by $P<.0001$. See text for more statistical comparisons.

power. Thus, the lack of consistent effect on survival cannot be explained and may simply reflect biological variability. Nonetheless, all developmental endpoints were clearly PPAR $\alpha$ dependent. The dependence of the developmental effects of PFNA on PPAR $\alpha$ is not unique, as this has also been demonstrated previously for PFOA [30]. However, not all PFAAs depend upon PPAR $\alpha$ to induce developmental effects. The developmental effects of PFOS, for example, were not found to be dependent on PPAR $\alpha$ [31]. This may be due to the sulfonated head group of PFOS, and thus PPAR $\alpha$ dependence may be a feature of the perfluorocarboxylic acids.

Mode of action differences between the perfluorinated carboxylic acids, PFOA and PFNA, and the sulfonate PFOS may also be evident in the pattern of neonatal loss observed following exposure to these compounds. PFNA exposure in WT mice resulted in a drastically reduced number of viable pups at birth with a continued loss of pups within the first few days, followed by a gradual loss until PND 10. Similarly,
PFOA induced a sudden loss of viable pups within the first few days of life, with a gradual loss over 10 days in CD1 mice [38] and 14 days in the 129S/SvlmJ strain [30]. In contrast to our study, PFNA in CD-1 mice induced a gradual loss of pups over the course of 12 days with no significant loss at birth [21]. This difference may be due to the increased sensitivity of the 129S/SvlmJ strain. Although survival curves for PFOA and PFNA can follow a course of up to 10-14 days, in utero exposure to PFOS results in a sudden loss of viability in pups within the first few hours after birth through postnatal day 2 in the rat $[35,36]$. These pups were observed to be in respiratory distress and displayed poor inflation of the lungs $[36,39]$ although the precise mechanism has not been found. This two day loss of pups after exposure to PFOS was observed in the $129 \mathrm{~S} / \mathrm{SvlmJ}$ strain as well, and only in $\mathrm{KO}$ did a few more die as late as PND 10 [31]. Therefore, in neonates, PFNA may be utilizing the same mechanism of action as other perfluorinated carboxylates while sulfonates such as PFOS utilize another. 


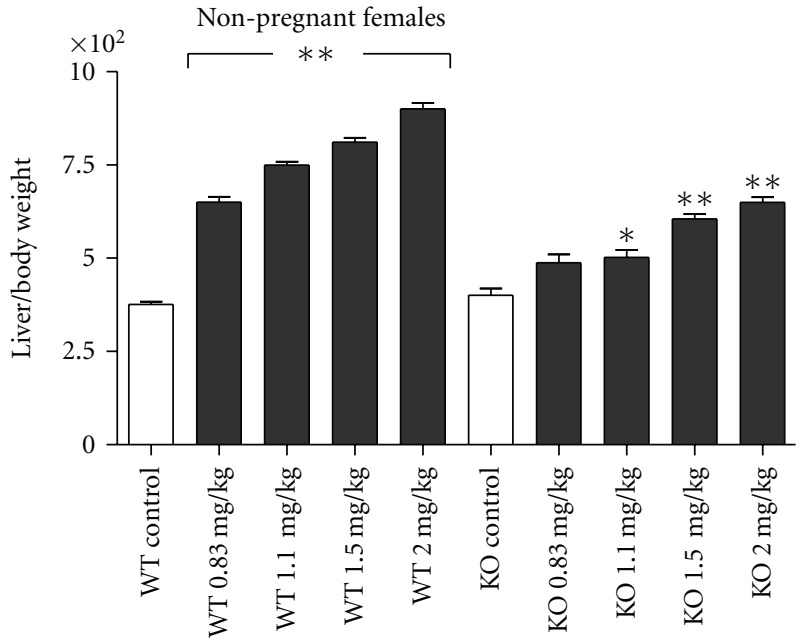

(a)

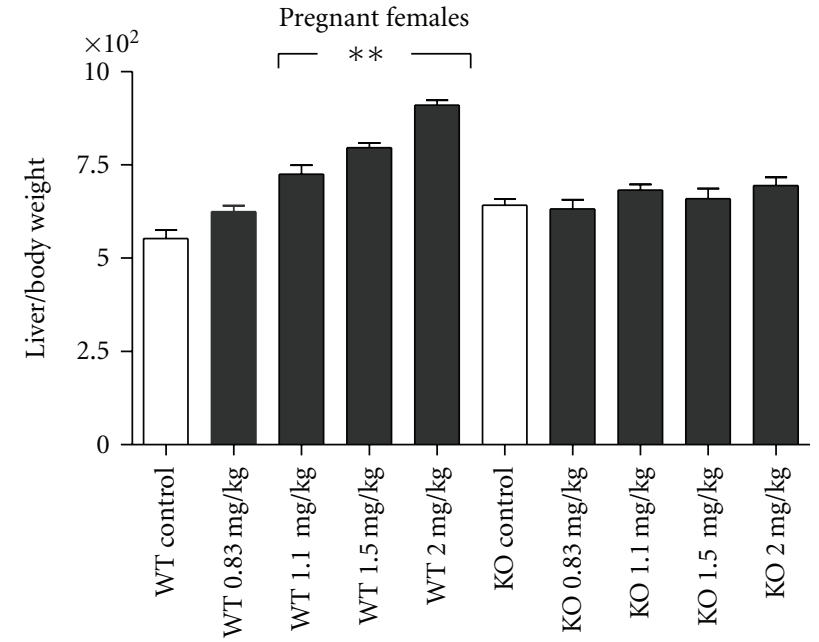

(b)

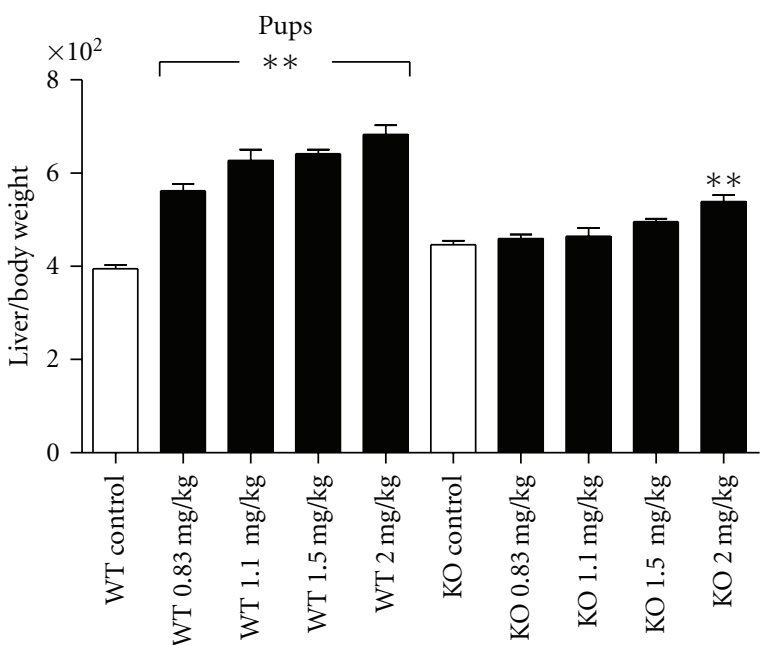

(c)

FIgURE 4: Effects of gestational exposure to PFNA on relative liver weight of the wild-type (WT) and PPAR $\alpha$ knockout (KO) nonpregnant adult female (a) dams (b) and pups (c) Measurements were taken on all individual adult females and on two pups per litter at weaning (i.e., 23 days after last dose or postnatal day 21). Data represent means or litter means \pm SEM. Relative liver weight was calculated as the absolute liver weight/body weight $\times 100$ for each data point. Relative liver weight was increased by PFNA exposure in both pregnant and non-pregnant adults and pups in all treated groups in the WT while only in the nonpregnant adult $\mathrm{KO}$ at 1.1 to $2 \mathrm{mg} / \mathrm{kg}$ and in the KO pup at $2.0 \mathrm{mg} / \mathrm{kg}$. Significant differences were found by ANOVA, and differences between groups were found by Bonferroni's test for multiple comparisons. Asterisks denote significant differences compared to controls $\left({ }^{*} P<.05,{ }^{* *} P<.001\right)$.

In the liver, there appear to be PPAR $\alpha$-independent as well as PPAR $\alpha$-dependent events in response to PFNA. PFNA was found to increase relative and absolute liver weight in the WT adult, but to a lesser extent in the nonpregnant KO, and not at all in the pregnant $\mathrm{KO}$ adult. The lack of effect on liver weight in the pregnant $\mathrm{KO}$ may suggest that the effects of PFNA on liver weight in adult $\mathrm{KO}$ mice are modest and were masked by the increase in liver weight due to pregnancy. The attenuated response in the KO liver compared to the WT liver is more obvious in the pup and may imply a separate, less efficient mechanism independent of PPAR $\alpha$. Similarly, less robust effects on liver weight in KO compared to WT mice were observed after exposure to PFOA [30]. Histopathological examination of those livers revealed a difference in histology of treated KO livers compared to treated WT livers [40], suggesting a different mechanism in KO mice. Other pathways suggested have included constitutive androstane receptor (CAR) and pregnane $\mathrm{X}$ receptor (PXR) [41-43], both present in humans. Therefore, PFNA may primarily utilize PPAR $\alpha$ to increase liver weight while relying upon other pathways in the absence of PPAR $\alpha$. Involvement of PPAR $\alpha$ in the liver may be a mechanism utilized by other PFAAs, since perfluorobutyrate also increased liver weight and induced hepatocyte hypertrophy dependent on 
$\operatorname{PPAR} \alpha$ [44]. Relevance of the PPAR $\alpha$ mechanism to humans has been criticized primarily based on the lower number of these receptors in the liver of human versus mouse. However, PPAR $\alpha$ is implicated here in the developmental effects of PFNA as well, and the etiology of PPAR $\alpha$ in other tissues of the embryo, fetus and neonate of the human and the mouse that are involved in gross development has not been fully determined. Therefore, the possibility of relevance of PPAR $\alpha$ to a human response to PFNA cannot be dismissed.

The levels of PFNA in the serum of pups, nursing dams, and adult females with no pups illustrate some interesting findings. First, the dose-dependent serum levels of PFNA in all groups of animals reflect the dose-dependent effects observed in dams and pups. Second, the effects observed in WT pups were not due to higher concentrations of PFNA in their system, since serum levels of PFNA were actually lower in WT pups than in KO pups at all doses. Conversely, the general lack of developmental effects in $\mathrm{KO}$ pups was not due to impaired pharmacokinetic distribution of PFNA to the pup. Another important observation is the possibility of substantial transfer of PFNA from dam to pup through milk. PFNA can enter milk, as evidenced by the finding of PFNA in the milk of humans [45-47], rats [48], and mice [49]. The lower serum PFNA levels in lactating dams compared to nonlactating adult females at weaning suggest an elimination of PFNA from the dams through placental transfer and through the milk. In addition, PFNA levels were elevated in pups compared to their mothers. This has also been reported for PFOA, in which an increased body burden was observed in the pups from birth to postnatal day 8 [49]. However, the contribution of placental versus lactational transfer of PFNA cannot be determined by the design of this study. Serum levels of PFNA in this mouse model were much higher than those of humans [7] but were measured to compare with the physiological effects observed and not to compare to human levels.

PFNA was found in this study to be a liver and developmental toxicant comparable in strength to other PFAAs, as adverse responses were elicited at maternal doses as low as $0.83 \mathrm{mg} / \mathrm{kg}$. In the CD- 1 mouse, PFNA appears to be more potent than PFOA. PFNA reduced CD-1 pup survival at $5 \mathrm{mg} / \mathrm{kg} /$ day, compared to $10 \mathrm{mg} / \mathrm{kg} /$ day by PFOA, and delayed eye opening at $3 \mathrm{mg} / \mathrm{kg} /$ day compared to $5 \mathrm{mg} / \mathrm{kg} /$ day by PFOA $[21,34,37,38]$. In vitro analysis of PPAR $\alpha$ activation shows PFNA to be more potent than PFOA as well [28]. The 129S strain used in the current study was used as an animal model for investigating mechanisms of action rather than for relative potency, as toxicity and PBPK data are lacking and this strain appears to be more sensitive to PFAAs. It is also clear that PFNA is more potent than PFOS. PFOS induced a $50 \%$ reduction in survival in CD1 offspring at $10 \mathrm{mg} / \mathrm{kg} / \mathrm{day}$ [35] and at $8.5 \mathrm{mg} / \mathrm{kg} / \mathrm{day}$ in 129 S/SvlmJ mice [31] whereas PFNA reduced survival at $1.1 \mathrm{mg} / \mathrm{kg} /$ day in the current study or $5 \mathrm{mg} / \mathrm{kg}$ in CD-1 mice. Given the lower activity of the sulfonated PFAA compared to the carboxylated PFAA on $\operatorname{PPAR} \alpha$ in vitro [28], lower potency in vivo may be expected for other sulfonated PFAAs as well.

\section{Conclusion}

In summary, PFNA is a developmental toxicant in mice, and the developmental effects are dependent upon expression of PPAR $\alpha$. The general pattern of effects observed in the mouse after gestational PFNA exposure mirrors the effects of other PFAAs, most closely that of PFOA. In addition, the differential response to PFNA in the livers of WT and KO adult females suggests a PPAR $\alpha$-dependent mode of action for increased liver weight, although additional pathways and mechanisms appear to be involved.

\section{Acknowledgments}

The authors gratefully acknowledge Amy Delinsky, Andrew Lindstrom, and Mark Strynar for analyzing PFNA in serum by MS/HPLC; John Rogers, Jason Stanko, and Kaberi Das for assistance with animal work; Jennifer Seed and Mitch Rosen for careful review of this paper.

\section{References}

[1] E. Kissa, Fluorinated Surfactants and Repellents, Marcel Dekker, New York, NY, USA, 2nd edition, 2001.

[2] J. P. Giesy and K. Kannan, "Perfluorochemical surfactants in the environment," Environmental Science and Technology, vol. 36, no. 7, pp. 146A-152A, 2002.

[3] R. Renner, "Growing concern over perfluorinated chemicals," Environmental Science and Technology, vol. 35, no. 7, pp. 154A-160A, 2001.

[4] A. M. Seacat, P. J. Thomford, K. J. Hansen, G. W. Olsen, M. T. Case, and J. L. Butenhoff, "Subchronic toxicity studies on perfluorooctanesulfonate potassium salt in cynomolgus monkeys," Toxicological Sciences, vol. 68, no. 1, pp. 249-264, 2002.

[5] M. Shoeib, T. Harner, B. H. Wilford, K. C. Jones, and J. Zhu, "Perfluorinated sulfonamides in indoor and outdoor air and indoor dust: occurrence, partitioning, and human exposure," Environmental Science and Technology, vol. 39, no. 17, pp. 6599-6606, 2005.

[6] C. Lau, K. Anitole, C. Hodes, D. Lai, A. Pfahles-Hutchens, and J. Seed, "Perfluoroalkyl acids: a review of monitoring and toxicological findings," Toxicological Sciences, vol. 99, no. 2, pp. 366-394, 2007.

[7] A. M. Calafat, Z. Kuklenyik, J. A. Reidy, S. P. Caudill, J. S. Tully, and L. L. Needham, "Serum concentrations of 11 polyfluoroalkyl compounds in the U.S. population: data from the National Health and Nutrition Examination Survey (NHANES) 1999-2000," Environmental Science and Technology, vol. 41, no. 7, pp. 2237-2242, 2007.

[8] K. S. Guruge, S. Taniyasu, N. Yamashita et al., "Perfluorinated organic compounds in human blood serum and seminal plasma: a study of urban and rural tea worker populations in Sri Lanka," Journal of Environmental Monitoring, vol. 7, no. 4, pp. 371-377, 2005.

[9] K. Hart, K. Kannan, L. Tao, S. Takahashi, and S. Tanabe, "Skipjack tuna as a bioindicator of contamination by perfluorinated compounds in the oceans," Science of the Total Environment, vol. 403, no. 1-3, pp. 215-221, 2008. 
[10] K. Kannan, L. Tao, E. Sinclair, S. D. Pastva, D. J. Jude, and J. P. Giesy, "Perfluorinated compounds in aquatic organisms at various trophic levels in a Great Lakes food chain," Archives of Environmental Contamination and Toxicology, vol. 48, no. 4, pp. 559-566, 2005.

[11] G. W. Olsen, H.-Y. Huang, K. J. Helzlsouer, K. J. Hansen, J. L. Butenhoff, and J. H. Mandel, "Historical comparison of perfluorooctanesulfonate, perfluorooctanoate, and other fluorochemicals in human blood," Environmental Health Perspectives, vol. 113, no. 5, pp. 539-545, 2005.

[12] M. Smithwick, S. A. Mabury, K. R. Solomon et al., "Circumpolar study of perfluoroalkyl contaminants in polar bears (Ursus maritimus)," Environmental Science and Technology, vol. 39, no. 15 , pp. 5517-5523, 2005.

[13] M. E. Andersen, J. L. Butenhoff, S.-C. Chang et al., "Perfluoroalkyl acids and related chemistries-toxicokinetics and modes of action," Toxicological Sciences, vol. 102, no. 1, pp. 314, 2008.

[14] CDC, "Fourth national report on human exposure to environmental chemicals,” 2009, http://www.cdc.gov/exposurereport/pdf/FourthReport.pdf.

[15] A. Kärrman, K. H. Harada, K. Inoue, T. Takasuga, E. Ohi, and A. Koizumi, "Relationship between dietary exposure and serum perfluorochemical (PFC) levels-a case study," Environment International, vol. 35, no. 4, pp. 712-717, 2009.

[16] P. Weihe, K. Kato, A. M. Calafat et al., "Serum concentrations of polyfluoroalkyl compounds in Faroese whale meat consumers," Environmental Science and Technology, vol. 42, no. 16, pp. 6291-6295, 2008.

[17] K. Kleszczyński, P. Stepnowski, and A. C. Składanowski, "Mechanism of cytotoxic action of perfluorinated acids. II. Disruption of mitochondrial bioenergetics," Toxicology and Applied Pharmacology, vol. 235, no. 2, pp. 182-190, 2009.

[18] N. Kudo, E. Suzuki-Nakajima, A. Mitsumoto, and Y. Kawashima, "Responses of the liver to perfluorinated fatty acids with different carbon chain length in male and female mice: in relation to induction of hepatomegaly, peroxisomal $\beta$-oxidation and microsomal 1-acylglycerophosphocholine acyltransferase," Biological and Pharmaceutical Bulletin, vol. 29, no. 9, pp. 1952-1957, 2006.

[19] X. Fang, L. Zhang, Y. Feng, Y. Zhao, and J. Dai, "Immunotoxic effects of perfluorononanoic acid on BALB/c mice," Toxicological Sciences, vol. 105, no. 2, pp. 312-321, 2008.

[20] J. C. DeWitt, A. Shnyra, M. Z. Badr et al., "Immunotoxicity of perfluorooctanoic acid and perfluorooctane sulfonate and the role of peroxisome proliferator-activated receptor alpha," Critical Reviews in Toxicology, vol. 39, no. 1, pp. 76-94, 2009.

[21] C. Lau, K. P. Das, K. Tatum, D. Zehr, C. R. Wood, and M. B. Rosen, "Developmental toxicity of perfluorononanoic acid in the mouse," Toxicologist, vol. 108, p. 417, 2009.

[22] P. Escher and W. Wahli, "Peroxisome proliferator-activated receptors: insight into multiple cellular functions," Mutation Research, vol. 448, no. 2, pp. 121-138, 2000.

[23] J. E. Klaunig, M. A. Babich, K. P. Baetcke et al., "PPAR $\alpha$ agonist-induced rodent tumors: modes of action and human relevance," Critical Reviews in Toxicology, vol. 33, no. 6, pp. 655-780, 2003.

[24] J. C. DeWitt, C. B. Copeland, M. J. Strynar, and R. W. Luebke, "Perfluorooctanoic acid-induced immunomodulation in adult C57BL/6J or C57BL/6N female mice," Environmental Health Perspectives, vol. 116, no. 5, pp. 644-650, 2008.
[25] D. E. Keil, T. Mehlmann, L. Butterworth, and M. M. Pedenadams, "Gestational exposure to perfluorooctane sulfonate suppresses immune function in B6C3F1 mice," Toxicological Sciences, vol. 103, no. 1, pp. 77-85, 2008.

[26] M. L. Takacs and B. D. Abbott, "Activation of mouse and human peroxisome proliferator-activated receptors $(\alpha, \beta / \delta$, $\gamma$ ) by perfluorooctanoic acid and perfluorooctane sulfonate," Toxicological Sciences, vol. 95, no. 1, pp. 108-117, 2007.

[27] J. P. Vanden Heuvel, J. T. Thompson, S. R. S. R. Frame, and P. J. Gillies, "Differential activation of nuclear receptors by perfluorinated fatty acid analogs and natural fatty acids: a comparison of human, mouse, and rat peroxisome proliferator-activated receptor- $\alpha,-\beta$, and $-\gamma$, liver $\mathrm{X}$ receptor- $\beta$, and retinoid $\mathrm{X}$ receptor- $\alpha$," Toxicological Sciences, vol. 92, no. 2, pp. 476-489, 2006.

[28] C. J. Wolf, M. L. Takacs, J. E. Schmid, C. Lau, and B. D. Abbott, "Activation of mouse and human peroxisome proliferatoractivated receptor alpha by perfluoroalkyl acids of different functional groups and chain lengths," Toxicological Sciences, vol. 106, no. 1, pp. 162-171, 2008.

[29] J. M. Keller, P. Collet, A. Bianchi et al., "Implications of peroxisome proliferator-activated receptors (PPARS) in development, cell life status and disease," International Journal of Developmental Biology, vol. 44, no. 5, pp. 429-442, 2000.

[30] B. D. Abbott, C. J. Wolf, J. E. Schmid et al., "Perfluorooctanoic acid-induced developmental toxicity in the mouse is dependent on expression of peroxisome proliferator-activated receptor-alpha," Toxicological Sciences, vol. 98, no. 2, pp. 571$581,2007$.

[31] B. D. Abbott, C. J. Wolf, K. P. Das et al., "Developmental toxicity of perfluorooctane sulfonate (PFOS) is not dependent on expression of peroxisome proliferator activated receptoralpha (PPAR $\alpha$ ) in the mouse," Reproductive Toxicology, vol. 27, no. 3-4, pp. 258-265, 2009.

[32] M. G. Narotsky and R. J. Kavlock, "A multidisciplinary approach to toxicological screening: II. Developmental toxicity," Journal of Toxicology and Environmental Health, vol. 45, no. 2, pp. 145-171, 1995.

[33] C. Lau, J. R. Thibodeaux, R. G. Hanson et al., "Effects of perfluorooctanoic acid exposure during pregnancy in the mouse," Toxicological Sciences, vol. 90, no. 2, pp. 510-518, 2006.

[34] C. Lau, J. R. Thibodeaux, R. G. Hanson et al., "Exposure to perfluorooctane sulfonate during pregnancy in rat and mouse. II: postnatal evaluation," Toxicological Sciences, vol. 74, no. 2, pp. 382-392, 2003.

[35] R. C. Grasty, D. C. Wolf, B. E. Grey, C. S. Lau, and J. M. Rogers, "Prenatal window of susceptibility to perfluorooctane sulfonate-induced neonatal mortality in the Sprague-Dawley rat," Birth Defects Research Part B, vol. 68, no. 6, pp. 465-471, 2003.

[36] K. P. Das, B. E. Grey, R. D. Zehr et al., "Exposure to perfluorononanoic acid during pregnancy: Evaluation of rat model," submitted to Reproductive Toxicology.

[37] K. R. Tatum, R. Zehr, K. Das et al., "Comparative pharmacokinetics of perfluorononanoic acid in rats and mice," Toxicologist, vol. 108, p. 197, 2009.

[38] C. J. Wolf, S. E. Fenton, J. E. Schmid et al., "Developmental toxicity of perfluorooctanoic acid in the CD-1 mouse after cross-foster and restricted gestational exposures," Toxicological Sciences, vol. 95, no. 2, pp. 462-473, 2007.

[39] R. C. Grasty, J. A. Bjork, K. B. Wallace, C. S. Lau, and J. M. Rogers, "Effects of prenatal perfluorooctane sulfonate 
(PFOS) exposure on lung maturation in the perinatal rat," Birth Defects Research Part B, vol. 74, no. 5, pp. 405-416, 2005.

[40] D. C. Wolf, T. Moore, B. D. Abbott et al., "Comparative hepatic effects of perfluorooctanoic acid and WY 14,643 in PPAR- $\alpha$ knockout and wild-type mice," Toxicologic Pathology, vol. 36, no. 4, pp. 632-639, 2008.

[41] X. Cheng and C. D. Klaassen, "Perfluorocarboxylic acids induce cytochrome $\mathrm{P} 450$ enzymes in mouse liver through activation of PPAR- $\alpha$ and CAR transcription factors," Toxicological Sciences, vol. 106, no. 1, pp. 29-36, 2008.

[42] H. Ren, B. Vallanat, D. M. Nelson et al., "Evidence for the involvement of xenobiotic-responsive nuclear receptors in transcriptional effects upon perfluoroalkyl acid exposure in diverse species," Reproductive Toxicology, vol. 27, no. 3-4, pp. 266-277, 2009.

[43] M. B. Rosen, J. S. Lee, H. Ren et al., "Toxicogenomic dissection of the perfluorooctanoic acid transcript profile in mouse liver: evidence for the involvement of nuclear receptors PPAR $\alpha$ and CAR," Toxicological Sciences, vol. 103, no. 1, pp. 46-56, 2008.

[44] J. E. Foreman, S.-C. Chang, D. J. Ehresman et al., "Differential hepatic effects of perfluorobutyrate mediated by mouse and human PPAR- $\alpha$," Toxicological Sciences, vol. 110, no. 1, pp. 204-211, 2009.

[45] A. Kärrman, I. Ericson, B. VanBavel et al., "Exposure of perfluorinated chemicals through lactation: levels of matched human milk and serum and a temporal trend, 1996-2004, in Sweden," Environmental Health Perspectives, vol. 115, no. 2, pp. 226-230, 2007.

[46] Z. Kuklenyik, J. A. Reich, J. S. Tully, L. L. Needham, and A. M. Calafat, "Automated solid-phase extraction and measurement of perfluorinated organic acids and amides in human serum and milk," Environmental Science and Technology, vol. 38, no. 13, pp. 3698-3704, 2004.

[47] M. K. So, N. Yamashita, S. Taniyasu et al., "Health risks in infants associated with exposure to perfluorinated compounds in human breast milk from Zhoushan, China," Environmental Science and Technology, vol. 40, no. 9, pp. 2924-2929, 2006.

[48] P. M. Hinderliter, E. Mylchreest, S. A. Gannon, J. L. Butenhoff, and G. L. Kennedy Jr., "Perfluorooctanoate: placental and lactational transport pharmacokinetics in rats," Toxicology, vol. 211, no. 1-2, pp. 139-148, 2005.

[49] S. E. Fenton, J. L. Reiner, S. F. Nakayama et al., "Analysis of PFOA in dosed CD-1 mice. Part 2: disposition of PFOA in tissues and fluids from pregnant and lactating mice and their pups," Reproductive Toxicology, vol. 27, no. 3-4, pp. 365-372, 2009. 


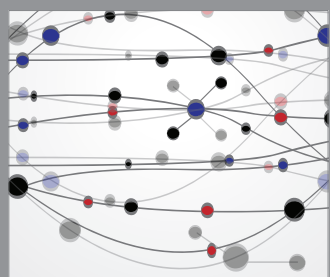

The Scientific World Journal
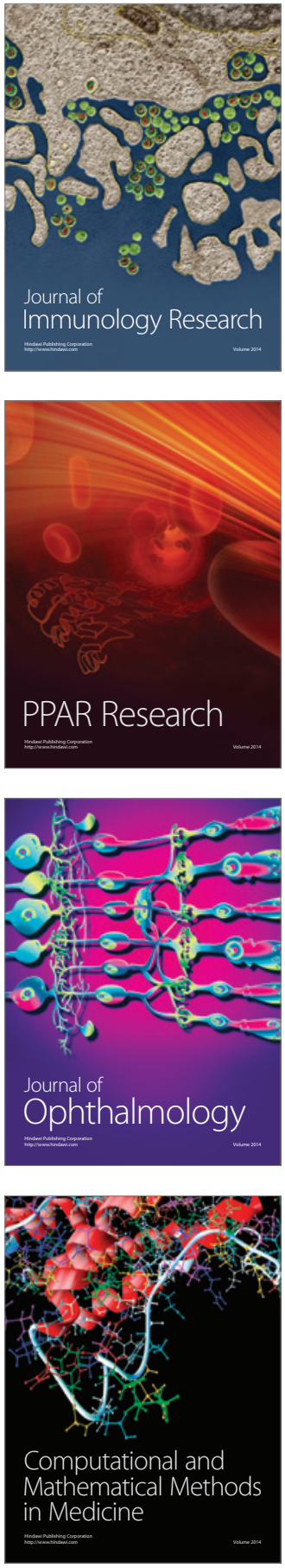

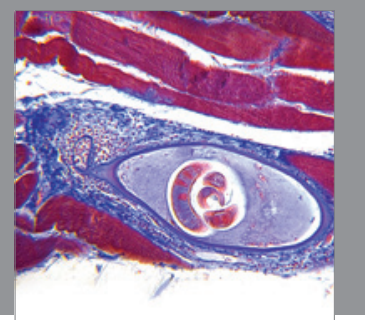

Gastroenterology

Research and Practice
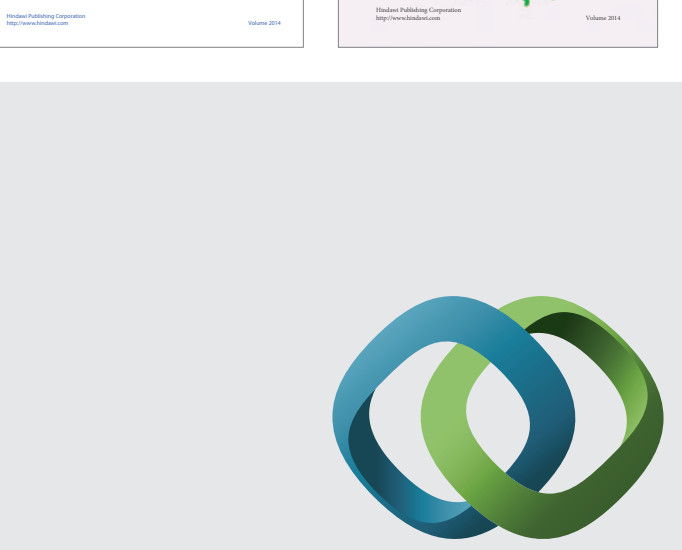

\section{Hindawi}

Submit your manuscripts at

http://www.hindawi.com
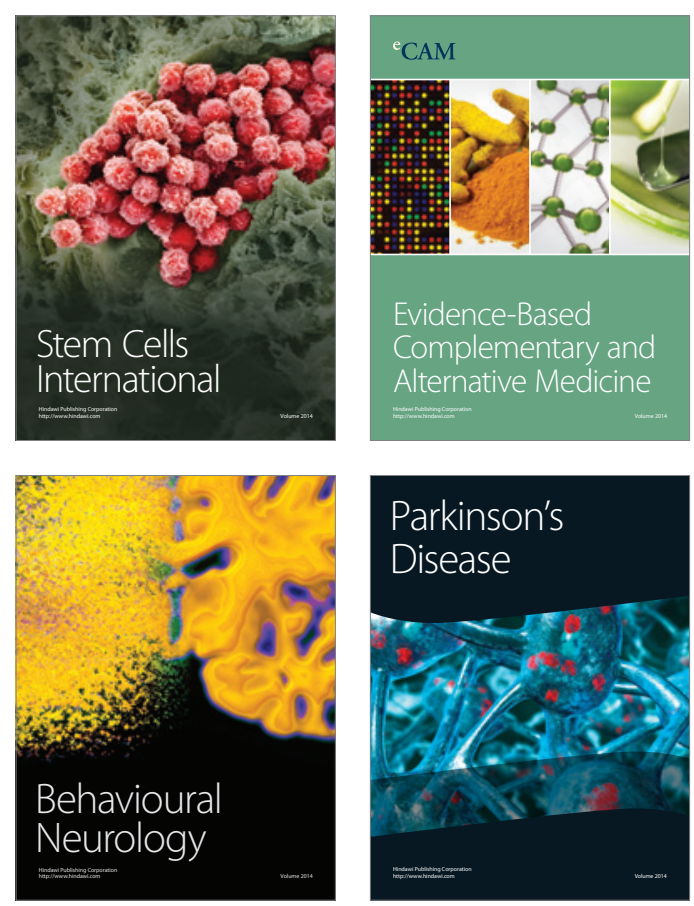

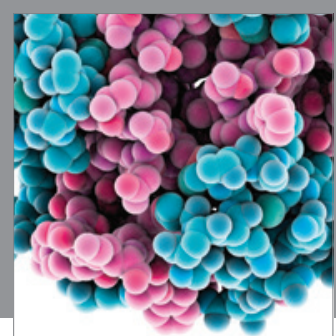

Journal of
Diabetes Research

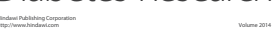

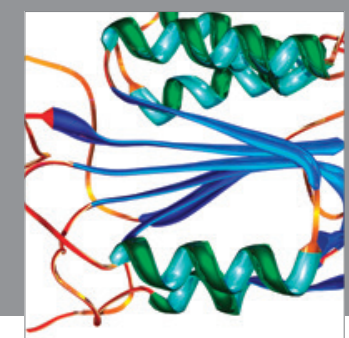

Disease Markers
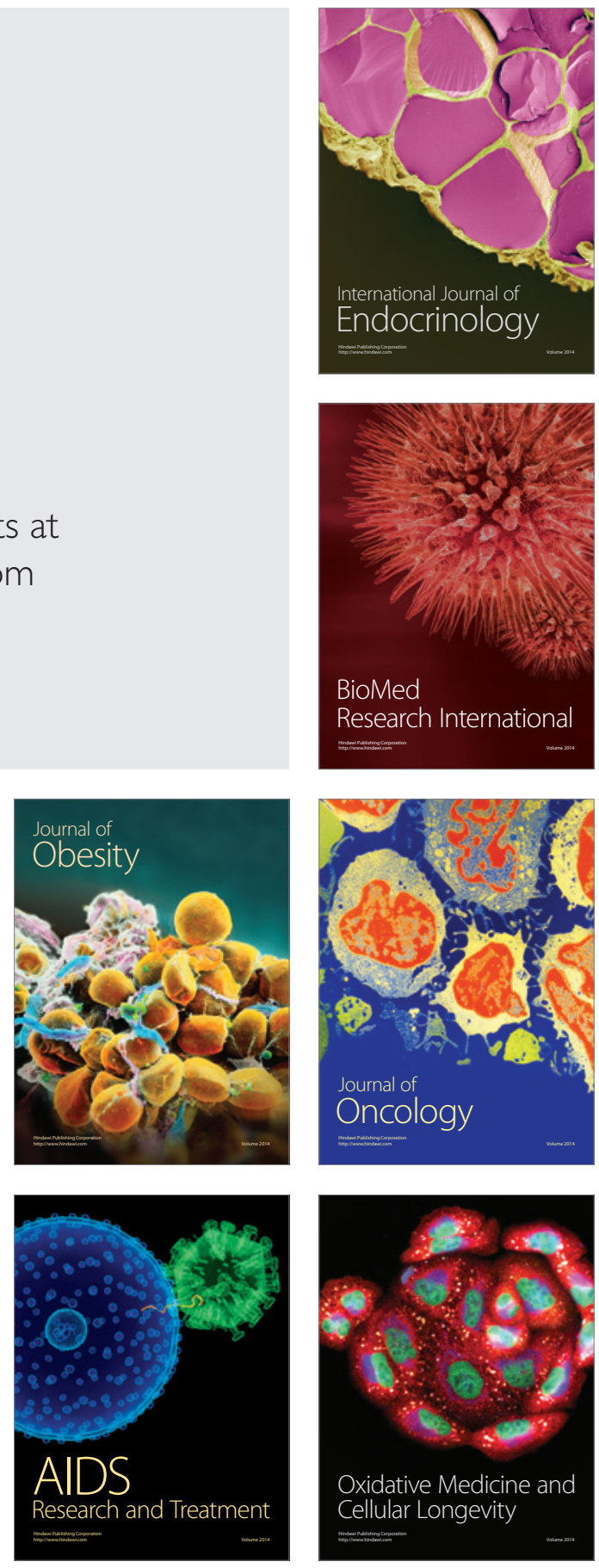